\title{
Rising incidence of type 1 diabetes in Scottish children, 1984-93
}

Jayanti J Rangasami, Darren C Greenwood, Brenda McSporran, Peter J Smail, Chris C Patterson, Norman R Waugh, on behalf of the Scottish Study Group for the Care of Young Diabetics

\begin{abstract}
Objectives-To calculate the incidence of type 1 diabetes in Scottish children aged less than 15 years between 1984 and 1993; to examine changes in incidence; and to calculate the prevalence of diabetes at the end of this period.

Design-Three data sources were used to construct the Scottish Study Group for the Care of Young Diabetics register: active reporting of all new cases; reports from the Scottish Morbidity Register 1; and local registers.

Subjects-All children resident in Scotland diagnosed with primary insulin dependent diabetes mellitus when less than 15 years of age between 1984 and 1993 .

Main outcome measures-Annual incidence and prevalence rate for Scotland; time trend in incidence over the 10 years; differences in incidence between the three different age groups; and completeness of the register.
\end{abstract}

Results-The average annual incidence for Scotland was 23.9/100 000 children. The prevalence rate was $1.5 / 1000$ in 1993 . A total of 2326 cases was identified from the three sources. Capture-recapture analysis suggests a case ascertainment of $98.6 \%$. The annual incidence rates increased at a rate of $2 \%$ each year (rate ratio $=1.02,95 \%$ confidence interval (CI) 1.01 to 1.03$)$. The incidence was higher in boys than girls (rate ratio $=1.08,95 \%$ CI 1.00 to 1.18$)$, and the incidence rates increased with age: $15.3 / 100000 / y e a r$ for age $0-4$ years, 24.4 / 100 000/year for age 5-9 years, and 31.9/ 100 000/year for age 10-14 years.

Conclusions-The incidence of type 1 diabetes in Scotland is increasing and the prevalence is relatively high. These findings have important implications for health service resource allocation. The Scottish Study Group for the Care of Young Diabetics' register provides a base for monitoring and research.

(Arch Dis Child 1997;77:210-213)

Keywords: insulin dependent diabetes mellitus; environmental triggers; genetic susceptibility; prevalence

Several reports have shown an increase in the incidence of type 1 diabetes in the UK and other countries. ${ }^{12}$ This trend implicates an increasing influence of environmental trigger factors against a backdrop of genetic suscepti- bility. The incidence of insulin dependent diabetes mellitus (IDDM) in Europe is increasing rapidly, with the rate in many countries roughly doubling over the past 20 years. ${ }^{2}$ The highest reported rates have been in Finland and other Scandinavian countries. ${ }^{2}$ Temporal variations in children aged less than 15 years have been observed in most of Europe and the Western Pacific, but not in North America $^{3}$ or New Zealand (Canterbury). ${ }^{4}$ In the USA, Canada, and New Zealand the incidence of the disease has levelled off. In Scotland, however, the annual incidence of $13.8 / 100000$ children aged less than 19 years in 1968-76 increased to $21.0 / 100000$ children in $1977-83 . .^{5}$ These estimates may be criticised, however, as based on unvalidated hospital discharge data, and the first estimate relies on a correction for readmissions which were present in the series.

Partly in response to the increasing incidence of diabetes in children the Scottish Study Group for the Care of Young Diabetics (SSGCYD) was founded in 1983 by Professor Jim Farquhar, the late Oman Craig, and a Scotland wide group of 40 paediatricians and doctors with an interest in diabetes in young patients. In 1985 the SSGCYD started a diabetic register with active reporting of newly diagnosed children. Changes of address and deaths are also notified to the register. The main aims of this study were to calculate an accurate incidence and prevalence rate, to examine temporal variations, and to estimate the ascertainment rate of our data.

\section{Methods}

SSGCYD REGISTER

The SSGCYD register started collecting data from 1 January 1985. Computerised data are entered by a research nurse (previously by a clerk). All paediatricians, doctors who look after young patients with diabetes, nurses specialising in diabetes, and dietitians are requested to report to this register by completing a postcard with the patient's name, sex, date of birth, address with postcode, case note number, hospital consultant, treatment hospital, date of diagnosis, and where diagnosed. Change of address and death are informed by another similar card. Each hospital receives an updated version of the register twice a year and can then cross check against their own local list. Patients missing from the list can then be registered. 
Table 1 Number of cases of type 1 diabetes in 1984-93 among children aged 0-14 years identified from active reporting, local registers, and SMR 1 discharge data

\begin{tabular}{lll}
\hline & \multicolumn{2}{l}{ Active reporting and local registers } \\
\cline { 2 - 3 } & Yes & No \\
\hline $\begin{array}{ll}\text { SMR 1 discharge data } \\
\text { Yes }\end{array}$ & 1779 & 395 \\
No & 152 & $?$ \\
\hline
\end{tabular}

Estimated completeness: $98.6 \%$ (95\% CI 98.0 to $99.1 \%$ ).

SMR1 DISCHARGE DATA SET

This computerised register contains details of all non-psychiatric inpatient discharges from Scottish hospitals since 1968. This register is searched periodically to identify all children with a discharge diagnosis of diabetes. This list is then matched against the SSGCYD register list and all names missing from the SSGCYD list are traced. These 'missing' patients are traced through each hospital by writing to each consultant or the nurse specialising in diabetes, or the dietician. All genuine cases are then entered into the SSGCYD register. It should be noted that the SMR1 data will only have names of children that are admitted to hospital either at diagnosis or subsequently.

LOCAL REGISTERS

Most hospitals in Scotland maintain their own local lists of patients with diabetes; some are manual registers, whereas others are computerised. These local registers were used as the third data set for constructing the SSGCYD register. We checked the SSGCYD list against these registers by contacting hospitals in person, and the few 'missing' patients were added to the SSGCYD register. All hospitals in the region were contacted to use their local register if they had one. Most were visited in person between 1992 and 1994, whereas others were contacted through the consultant, nurse specialising in diabetes, or dietitian. Through this thorough procedure we should have found all children diagnosed with diabetes between 1984 and 1993.

PREVALENCE

To calculate the prevalence, data for children diagnosed before 1984 were also used. The local registers were the most important source of prevalence data and completeness ascertained via SMR1 and the SSGCYD register. As a part of another study, all patients on the register were flagged with the General Register Office, which provides information on mortality and emigration. In this way the number of children aged less than 15 years living in Scotland on 31 December 1993 with a diagnosis of IDDM was calculated.
STATISTICAL METHODS

Incidence rates were calculated using the patients on the SSGCYD register and the estimated population each year by age and sex for Scotland published annually by the General Register Office for Scotland. The 1991 census population for Scotland was used to age standardise the annual incidence rates. The completeness of the register was estimated using capture-recapture analysis ${ }^{7}$ with active reporting and local registers were combined to give the primary source and SMR1 discharge data were used as the secondary source, both sources being statistically independent. Incidence was modelled using Poisson regression ${ }^{8}$ in EGRET, ${ }^{9}$ comparing incidence rates between boys and girls, between different age groups, and investigating linear trends over 10 years. The interaction between age group and sex was included to compare the distribution of age of incidence between sexes. The hypothesis that the age of incidence has changed over the 10 years was tested by adding the interaction between age group and the linear trend in year to the Poisson regression model, which included age, sex, and year effects. To investigate any seasonal variation in disease incidence Edwards' method was used. This assumes the variation follows a sinusoidal pattern. ${ }^{10}$

\section{Results}

The SSGCYD register between 1984 and 1993 contained 2326 children aged less than 15 years. A total of 1931 patients $(83.0 \%)$ were identified by active reporting and local registers and $2174(93.5 \%)$ were identified from SMR1 discharge data. A total of 1779 cases was common to both sets of sources (table 1). Capturerecapture analysis suggested that these sources achieved $98.6 \%$ case ascertainment (95\% confidence interval (CI) 98.0 to $99.1 \%$ ). The 2326 cases detected between 1984 and 1993 gave an overall average annual incidence of 23.9/ 100 000/year.

The register consisted of 1239 boys (average annual incidence 24.8/100 000/year) and 1087 girls (average annual incidence 22.9/100 000/ year). Table 2 shows the average annual incidence of type 1 diabetes during the 10 year period for boys and girls in five year age bands. In the Poisson model the difference in incidence between boys and girls was of borderline statistical significance at the conventional 5\% level (rate ratio $=1.08$, CI 1.00 to $1.18, p=0.05)$. From table 2 it appears that the higher incidence in boys is mainly attributable to an excess in the 10-14 years age group, but the difference in age of diagnosis between sexes (tested by including the interaction between

Table 2 Age and sex specific average annual incidence rates of type 1 diabetes in 1984-93 among children aged 0-14 years

\begin{tabular}{lllllll}
\hline \multirow{2}{*}{$\begin{array}{l}\text { Age group } \\
\text { (years) }\end{array}$} & No of cases & & & \multicolumn{4}{l}{ Average annual incidence rates/100 000 (95\% CI) } \\
\cline { 2 - 3 } \cline { 5 - 6 } \cline { 5 - 6 } & Boys & Girls & & Boys & Girls & Total \\
\hline $0-4$ & 260 & 236 & & $15.6(13.8$ to 17.7$)$ & $14.9(13.1$ to 16.9$)$ & $15.3(14.0$ to 16.7$)$ \\
$5-9$ & 393 & 385 & & $24.1(21.8$ to 26.6$)$ & $24.8(22.4$ to 27.4$)$ & $24.4(22.7$ to 26.2$)$ \\
$10-14$ & 586 & 466 & & $34.6(31.9$ to 37.6$)$ & $29.0(26.4$ to 31.7$)$ & $31.9(30.0$ to 33.9$)$ \\
All ages & 1239 & 1087 & & $24.8(23.5$ to 26.3$)$ & $22.9(21.6$ to 24.3$)$ & $23.9(22.9$ to 24.9$)$ \\
\hline
\end{tabular}


Table 3 Annual age standardised incidence rates of type 1 diabetes in 1984-93 among children aged 0-14 years

\begin{tabular}{|c|c|c|c|c|c|}
\hline \multirow[b]{2}{*}{ Year } & \multicolumn{2}{|c|}{ No of cases } & \multicolumn{3}{|c|}{ Age standardised incidence $100000 *(95 \% \mathrm{CI})$} \\
\hline & Boys & Girls & Boys & Girls & All \\
\hline 1984 & 121 & 117 & 22.2 (18.2 to 26.2$)$ & 23.4 (19.1 to 27.6$)$ & 22.7 (19.8 to 25.6$)$ \\
\hline 1985 & 116 & 110 & $22.0(18.0$ to 26.1$)$ & $22.2(18.0$ to 26.4$)$ & $22.1(19.2$ to 25.0$)$ \\
\hline 1986 & 118 & 92 & $23.3(19.1$ to 27.6$)$ & $19.2(15.3$ to 23.1$)$ & $21.3(18.4$ to 24.4$)$ \\
\hline 1987 & 133 & 87 & $26.7(22.1$ to 31.2$)$ & $18.4(14.5$ to 22.3$)$ & $22.6(19.6$ to 25.6$)$ \\
\hline 1988 & 131 & 95 & $26.7(22.1$ to 31.3$)$ & $20.6(16.4$ to 24.8$)$ & 23.7 (20.6 to 26.8$)$ \\
\hline 1989 & 126 & 113 & $25.9(21.3$ to 30.4$)$ & $24.5(20.0$ to 29.0$)$ & $25.2(22.0$ to 28.4$)$ \\
\hline 1990 & 118 & 119 & $24.2(19.8$ to 28.5$)$ & $25.7(21.1$ to 30.3$)$ & $24.9(21.7$ to 28.1$)$ \\
\hline 1991 & 115 & 106 & $23.4(19.1$ to 27.7$)$ & $22.7(18.3$ to 27.0$)$ & $23.0(20.0$ to 26.0$)$ \\
\hline 1992 & 126 & 130 & $25.4(20.9$ to 29.8$)$ & $27.6(27.8$ to 32.3$)$ & $26.4(23.2$ to 29.7$)$ \\
\hline 1993 & 135 & 118 & $27.0(22.4$ to 31.5$)$ & $25.0(20.5$ to 29.5$)$ & $26.0(23.3$ to 28.7$)$ \\
\hline
\end{tabular}

* Age standardised to 1991 census population for Scotland.

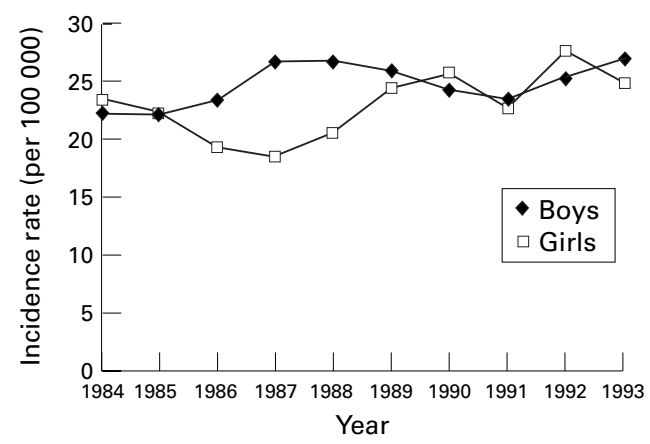

Figure 1 Annual age standardised incidence of type 1 diabetes in 1984-93 among children aged 0-14 years for boys and girls.

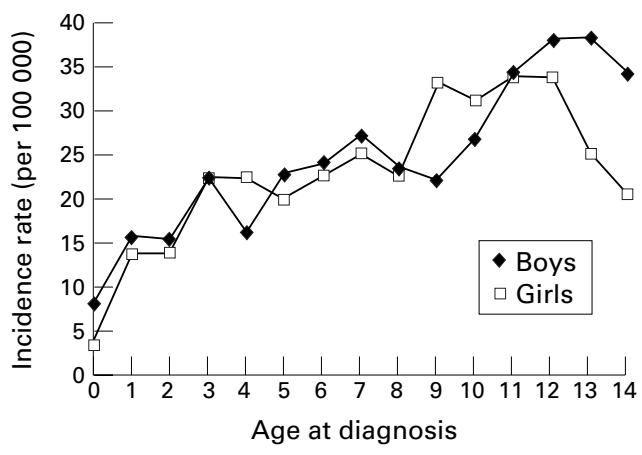

Figure 2 Age at diagnosis for type 1 diabetes in 1984-93 among children aged $0-14$ years.

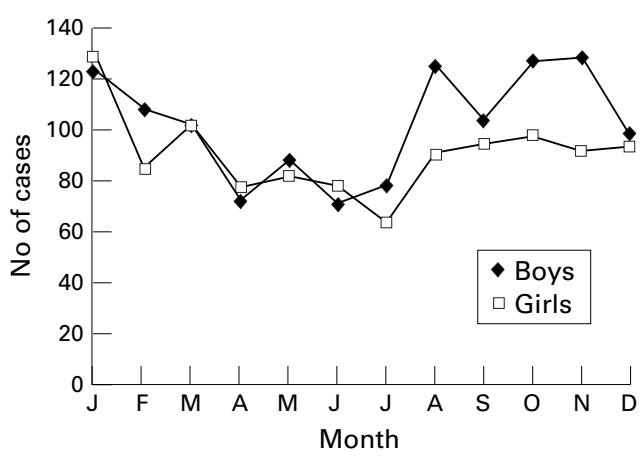

Figure 3 Number of children aged 0-14 years diagnosed with type 1 diabetes each month.

age group and sex in the model) was not statistically significant $\left(\chi^{2}=4.95\right.$ on two degrees of freedom, $\mathrm{p}=0.084)$.

ANNUAL INCIDENCE 1984-93

As shown in table 3, the incidence (standardised for age) increased over the 10 year period from $22.7 / 100000 /$ year in 1984 to $26.0 /$
$100000 /$ year in 1993. When the year of diagnosis was added to the Poisson model it showed a statistically significant increase in incidence of about $2 \%$ a year (rate ratio $=1.02$, $95 \%$ CI 1.01 to $1.03, p=0.009)$. Figure 1 shows the annual age standardised incidence rates. Actual numbers are given in table 3 .

AGE AT DIAGNOSIS

Though the mean age of diagnosis decreased markedly between 1984 (mean (SD) age 9.7 (3.7) years) and 1993 (8.4 (3.9) years), the distribution of age at diagnosis did not differ significantly over the 10 year period after taking account of changes in the population age structure. This was tested formally by adding the interaction term between age group and the linear trend in year to the Poisson model $\left(\chi^{2}=\right.$ 4.02 on two degrees of freedom, $p=0.13)$. An alternative interpretation of this test is that the trend in incidence did not differ significantly between the three age groups. Figure 2 shows incidence rate by age at diagnosis across the 10 year period.

MONTH OF DIAGNOSIS

Seasonal variation was apparent (Edwards' test $\chi^{2}=41.9$ on two degrees of freedom, $\mathrm{p}<$ 0.001). Numbers of cases each month, for each sex, are presented graphically in fig 3 . The month of diagnosis was not available in 12 children. A clear peak in incidence occurred in autumn/winter. This was true for both sexes, but only for children in the 5-9 and 10-14 year age groups.

PREVALENCE

There were 1448 prevalent cases of IDDM in Scotland in children aged less than 15 years on 31 December 1993. This gives a prevalence rate of $1.5 / 1000$ children.

\section{Discussion}

This study was conducted because of concern about the increasing incidence of type 1 IDDM in Scottish children. Two studies by Patterson and coworkers ${ }^{56}$ have shown an increasing incidence from 13.8/100 000/year between 1968 and 1976 and up to 21.0/100 000/year from 1977 to 1983 for children aged less than 19 years. The SSGCYD register was set up to address this issue. Our study found that the age standardised incidence had increased from $22.7 / 100000$ in 1984 to $26.0 / 100000$ in 1993, 
with an average annual incidence of 23.9/ 100 000/year. This increase of about $2 \%$ a year, though small, is statistically significant, and the effect over 10 years is a large increase.

The Scottish IDDM incidence is similar to that of Scandinavian countries. The incidence of IDDM in Finland at 35.6/100 000 in 1988 is the highest in the world ${ }^{11}$; Sweden at 23.1/ 100000 (1986) and Norway at 20.8/100 000 (1989) are also high. Sardinia, at 30.2/100 000 (1987), is second highest in the world. Some countries have reached a plateau, but we have shown that this is not true of Scotland where the incidence continues to increase. The rate of increase is now slower than that estimated to have occurred between 1968 and 1976, however. $^{5}$ Between 1977 and 1983 the increase, although not statistically significant, was at a rate similar to that recorded in the present study. ${ }^{6}$

The capture-recapture analysis showed that we have identified virtually all Scottish children aged 0-14 years with type 1 IDDM. Nationally, our study identified more cases than the study by Metcalfe and Baum in 1988 through the British Paediatric Surveillance Unit (BPSU) survey. ${ }^{12}$ They found 190 cases, giving an estimated incidence of 19.8/100 000, but we found 226 cases in that year from our three data sources, giving an age standardised incidence of 23.7/100000 (crude rate $=$ 23.6/100 000). The ascertainment as estimated by Patterson and Hadden ${ }^{13}$ for the BPSU survey and agreed by Metcalfe and Baum was $82 \%$. Wadsworth et al, with an estimated ascertainment of $99 \%$, found 51 cases in the $0-4$ year age group in $1992^{14}$ : we found three more cases. We also found six more cases than the total of 45 found by the BPSU study in 1988 among the 0-4 year age group. We therefore conclude that the three data sources used make the SSGCYD register more complete than other studies, which have underestimated the incidence of type 1 diabetes in Scotland.

The mean age of diagnosis decreased markedly between 1984 and 1993, but the mean age of the population also decreased, and taking this into account in the modelling, the age at diagnosis did not differ significantly over the 10 year period at the conventional 5\% level. Our study also showed a peak incidence in the 10-14 year age group at the beginning of puberty, as shown by other studies. ${ }^{15} 16$ The sex ratio shows a slight imbalance, the rate ratio for boys to girls being 1.08 (95\% CI 1.00 to 1.18 ). This reflects the higher incidence in boys $(24.8 / 100000)$ than girls $(22.9 / 100000)$.

The seasonal variation shows a clear peak in autumn/winter and trough in the summer. This was true for both sexes, but is less marked in younger children. This confirms other reports. ${ }^{15} 1718$
The increasing incidence is of concern because of its health and resource implications. In the absence of a cure for diabetes these children will become major consumers of ophthalmic and renal services in the future. They will also require close monitoring in the childhood years and beyond. Services will have to be developed to meet these increasing demands. There is also great research potential and more studies are required to look for the environmental trigger factors giving rise to such a high incidence in Scotland against a genetic predisposition. Further studies are also needed to monitor the future trends to provide information about future need for health care provision.

The authors thank the population statistics branch of the General Register Office and the information and statistics division of the Common Service Agency for Scotland for their assistance. We also thank all the doctors, nurses, and dieticians of the variWe also thank all the doctors, nurses, and dieticians of the vari-
ous hospitals in Scotland that were contacted. We thank Muriel ous hospitals in Scotland that were contacted. We thank Muriel
Mair for clerical assistance in the initial stages of setting up the Mair for clerical assistance in the initial stages of setting up the
register at Aberdeen. Source of funding: Novo Nordisc, King register at Aberdeen. Source of funding:
Edward Fund Raisers, Turiff, Scotland.

1 Green A, Gale EAM, Patterson CC. Incidence of childhoodonset insulin dependent diabetes mellitus: the EURODIAB onset insulin dependent diabetes melt

2 Bingley PJ, Gale EAM. Rising incidence of IDDM in Europe. Diabetes Care 1989;12:289-95.

3 Diabetes Epidemiology Research International Group. Secular trends in incidence of childhood IDDM in 10 countries. Diabetes 1990;39:858-64.

4 Scott RS, Brown LJ, Darlow BA, Forbes LV, Moore MP. Temporal variation in incidence of IDDM in Canterbury, New Zealand. Diabetes Care 1992;15:895-99.

5 Patterson CC, Thorogood M, Smith PG, Heasman MA, Clarke JA, Mann JI. Epidemiology of type 1 (insulindependent) diabetes in Scotland 1968-1976. Evidence of an increasing incidence. Diabetologia 1983;24:238-43.

6 Patterson CC, Smith PG, Webb J, Heasman MA, Mann JI. Geographical variation of diabetes mellitus in Scottish children during the period 1977-1983. Diabetic Med 1988;5:
dich dren d.

7 LaPorte RE. Assessing the human condition: capturerecapture techniques. BMF 1994;308:5-6.

8 Kleinbaum DG, Kupper LL, Muller KE. Applied regression analysis and other multivariate methods. 2nd Ed. Boston: Duxbury Press, 1988: 497-512.

9 Epidemiological graphics estimation and testing (EGRET). Seattle: Statistics and Epidemiology Research Corporation and Cytel Software Corporation, 1985-91.

10 Edwards $\mathrm{JH}$. The recognition and estimation of cyclic trends. Ann Hum Genet 1961;25:83-7.

11 Karvonen M, Tuomilehto J, Virtala E, et al. Seasonality in the clinical onset of insulin-dependent diabetes mellitus in Finnish children. Childhood Diabetes in Finland (DiMe) Study Group. Am f Epidemiol 1996;143:167-76.

12 Metcalfe MA, Baum JD. Incidence of insulin dependent diabetes in children aged under 15 years in the British Isles diabetes in children aged under 15 year

13 Patterson CC, Hadden DR. Incidence of insulin dependent diabetes in children under 15 years [letter]. BMF diabetes in child $1991 ; 302: 960-1$.

14 Wadsworth E, Shield J, Hunt L, Baum D. Insulin dependent diabetes in children under 5: incidence and ascertainment validation for 1992. BMF 1995;310:700-3

15 Jones G, Sovic O. Increasing incidence of diabetes mellitus in Norwegian children 0-14 years of age, 1973-1982. Diabetologia 1989;32:79-83.

16 Soltesz G, Madacsy D, Bekefi D, Danko L. Rising incidence of type 1 diabetes in Hungarian children (1978-1987). Diabet Med 1990;7:111-4.

17 Dahlquist G, Bloom I, Holmgren G, et al. The epidemiology of diabetes in Swedish children 0-14 years-a six-year prospective study. Diabetologia $1985 ; 28 \cdot 802-8$.

18 Rewers M, LaPorte RE, Walczak M, Dmochowski K, Bogaczynska E. Apparent epidemic of insulin dependent diabetes mellitus in midwestern Poland. Diabetes 1987;36: 106-13. 